\title{
Fruit Exocarp Phenols in Relation to Quiescence and Development of Monilinia fructicola Infections in Prunus spp.: A Role for Cellular Redox?
}

\author{
Miin-Huey Lee and Richard M. Bostock
}

\author{
Department of Plant Pathology, University of California, One Shields Ave., Davis 95616. \\ Current address of M.-H. Lee: Department of Plant Pathology, National Chung-Hsing University, No. 250 Kao-Kuang Rd., Taichung 402, \\ Taiwan. \\ Accepted for publication 28 August 2006.
}

\section{ABSTRACT}

Lee, M.-H., and Bostock, R. M. 2007. Fruit exocarp phenols in relation to quiescence and development of Monilinia fructicola infections in Prunus spp.: A role for cellular redox? Phytopathology 97:269-277.

\footnotetext{
Monilinia fructicola causes brown rot of Prunus species and usually remains quiescent on immature fruit but reactivates when fruit are mature. The dihydroxycinnamates caffeic acid and its quinate ester, chlorogenic acid, abundant in the exocarp of peach fruit, had no effect on fungal growth but markedly inhibited the production of the cell wall degrading enzymes polygalacturonase and cutinase in $M$. fructicola cultures. This inhibition was related to changes in the electrochemical redox potentials of the cultures, as measured with a redox electrode. Fungal culture filtrates had lower electrochemical redox potentials when the growth medium contained caffeic acid than in caffeic acid-free medium. Levels of total intracellular glutathione, the reduced form of which serves as a
}

major cellular antioxidant, increased significantly in $M$. fructicola cells in response to external caffeic acid. The presence of caffeic acid, chlorogenic acid, or reduced glutathione in conidial suspensions of $M$. fructicola did not inhibit germination on flower petals and fruit, but inhibited appressorium formation from germinated conidia and subsequent brown rot lesion development. These results suggest that intracellular antioxidant levels in the pathogen can be influenced by phenols present in host tissue and that changes in the redox environment may influence gene expression and differentiation of structures associated with infection by the pathogen. The possible relationship of host phenols to quiescence and subsequent development of $M$. fructicola infections is discussed.

Additional keywords: disease resistance, latent infection, postharvest diseases.
Monilinia fructicola (G. Wint.) Honey causes brown rot disease in species of Prunus, including most commercially important cultivars of peach, nectarine, cherry, plum, apricot, and almond. The fungus mainly infects blossoms and fruit, and the resulting disease can lead to significant yield losses. The susceptibility of peach fruit to brown rot disease is highly dependent on the developmental stage of the fruit. Fruit are most susceptible very early in development during rapid expansion of the pericarp and then again late in the season, particularly at harvest maturity after the endocarp has formed completely and the pericarp has completed another period of rapid expansion $(5,20)$. In the horticultural literature, these stages are often referred to as stage I and late stage III, respectively $(7,50)$. If fruit become infected early in the season, the pathogen usually remains quiescent during a period when fruit pericarp growth is slow but embryo development is rapid, with a concomitant lignification of the endocarp ("pit hardening"; stage II). These quiescent infections can reactivate when fruit are mature, often resulting in extensive colonization and severe brown rot (26).

Chemical and physical factors are thought to account for differences often observed in disease resistance among different fruit developmental stages (34). A number of studies attribute the differences to changes in the concentrations of compounds that are directly inhibitory to the pathogen. For example, unripe avocado is resistant to infection by Colletotrichum gloeosporioides, the causal agent of anthracnose disease. C. gloeosporioides infections remain quiescent and then reactivate as fruit ripen, during

Corresponding author: R. M. Bostock; E-mail address: rmbostock@ucdavis.edu

DOI: 10.1094/PHYTO-97-3-0269

(C) 2007 The American Phytopathological Society which there is pronounced turnover of a preformed antifungal diene (1-acetoxy-2-hydroxy-4-oxo-heneicosa-12,15-diene) $(35,36)$. $\alpha$-Tomatine, present at high levels in unripe tomato peels, is suggested to contribute to the resistance of unripe tomato to infection of Botrytis cinerea $(39,47)$. Similarly, changes in fruit surface architecture and chemistry, particularly in proanthocyanidins and sugar composition, appear to contribute to the progressive increase in susceptibility observed in grape berries and strawberries to $B$. cinerea $(19,21)$. Citral, a fungitoxic terpene aldehyde in the pericarp of citrus fruit, declines during maturation of lemons and lower concentrations of this compound are thought to explain in part the higher susceptibility of older mature fruit to Penicillium digitatum relative to younger fruit (40). More recently, the influence of ambient $\mathrm{pH}$ on pathogenicity of fruit pathogenic fungi has received attention, with the discovery that a number of secreted pathogenicity factors are controlled, in part, by environmental $\mathrm{pH}$ (reviewed in reference 38). Less studied is the influence of the ambient electrochemical redox potential on fungal growth, development, and pathogenicity, although it is clear that changes in the levels of reactive oxygen species and in the balance of other antioxidants and pro-oxidants in the environment can affect gene expression associated with growth and differentiation in fungi (1).

In a previous study, several phenols that are abundant at certain peach fruit developmental stages were evaluated for their effects on $M$. fructicola spore germination and mycelial growth in culture (6). Growth of M. fructicola was not affected by chlorogenic acid (CGA; 5-O-caffeoylquinic acid) or by caffeic acid (CA; 3,4dihydroxycinnamic acid) at levels similar to or in excess of those in the exocarp (i.e., cuticle, epidermis, and hypodermis; syn. epicarp) of immature resistant fruit (6). However, these plant phenolic compounds down-regulated $M f c u t l$ gene expression and 
inhibited cutinase production in cutin-induced $M$. fructicola cultures (48). Also, the CA moiety, and not the quinate moiety of CGA, was shown to be the active component of CGA responsible for the observed effects on $M$. fructicola responses, consistent with the functional importance of the phenolic ring and suggesting to us a possible role for the antioxidant properties of the molecule in the phenomenon.

We have investigated penetration by $M$. fructicola of different stone fruit organs and tissues. These studies have shown that $M$. fructicola produces appressoria on surfaces of some host tissues, that inhibitors of appressorium formation in vitro can also inhibit brown rot development on these same host tissues, and that genes encoding cutinase (Mfcut1; EC 3.1.1.74) and endopolygalacturonase (Mfpgl; EC 3.2.1.15) of M. fructicola appear to contribute to fungal pathogenesis $(24,25)$. We also observed that M. fructicola produced fewer appressoria on immature fruit (stage I) and mature fruit (stage III) than on fruit at an intermediate stage of development (stage II). The production of numerous appressoria on stage II fruit suggests they could play a role in quiescence, perhaps by serving as resting structures until fruit reach maturity.

We are trying to better understand how changes in fruit exocarp chemistry and structure influence quiescence and development of M. fructicola infections, with a current emphasis on naturally occurring phenols and antioxidants. The specific objectives of this study were (i) to quantify the effect of CGA and CA on appressorium formation, secreted cutinase and polygalacturonase (PG) activities, and brown rot development of M. fructicola; and (ii) to determine if the inhibitory effect of CGA and CA on the production of cell wall-degrading enzymes is related to the redox state as measured by the electrochemical potential of the growth medium and levels of the principal cellular antioxidant glutathione (GSH).

\section{MATERIALS AND METHODS}

Reagents. CA (Sigma C-0625) and CGA (Sigma C-3878) were prepared as $250 \mathrm{mM}$ stock solutions in methanol and passed through a $0.22 \mu \mathrm{m}$ filter to assure sterility (SLGVR25LS, Millipore Corp., Billerica, ME). Reagents for the detection of paranitrophenyl butyrate (PNB) hydrolysis were prepared as described previously (6). Reagents for PG activity assays including sodium acetate buffer, 2-cyanoacetamide, and sodium borate were prepared as described $(17,22)$. Reagents for GSH detection including NADPH (Sigma N-1630) and yeast GSH reductase (Roche Applied Science, Indianapolis, IN) were prepared on the day of use. Aliquots of 5,5'-dithiobis (2-nitrobenzoic acid) (DTNB, Sigma D-8130) and reduced GSH (Boehringer Mannheim Gmbh, Mannheim, Germany) were prepared by dissolving in water and stored at $-20^{\circ} \mathrm{C}$. Apple cutin was prepared as described previously (6).

Fungal strain and culture conditions. $M$. fructicola strain MUK1 was used in this study and grown on V8 juice agar plates at $25 \pm 2{ }^{\circ} \mathrm{C}$ as needed to produce conidia (6). Conidia from 7- to 10-day-old V8 cultures were collected with sterile water and passed through one layer of Miracloth (Calbiochem Co., San Diego, CA) to remove mycelia. The concentration of spore suspensions was determined with a hemacytometer. The modified Czapek-Dox media (6) containing $1 \%$ glucose (mCZ-glucose), $1 \%$ apple cutin (mCZ-cutin; cutinase-induction medium), or $4 \%$ citrus polygalacturonate (Sigma P-3850; mCZ-polygalacturonate; PG-induction medium) were prepared the day prior to inoculation. Cutin was prepared from apple peels as previously described (6). The medium was adjusted to $\mathrm{pH} 7.0$ with $\mathrm{NaOH}$ or $\mathrm{HCl}$ solution and placed into $250-\mathrm{ml}$ flasks with $50 \mathrm{ml}$ per flask. All flasks were covered with two layers of Whatman No. 1 filter paper (Fisher Scientific, Hampton, NH) and autoclaved for 15 min. Prior to inoculation, freshly prepared CA was added to the medium to a final concentration of $1 \mathrm{mM}$. Methanol was used as a control at a final concentration of $0.4 \%$. Each flask was inoculated with a $1 \times 10^{4}$ spores per ml suspension of $M$. fructicola obtained from a V8 agar culture as described previously. All flask cultures were incubated under ambient light at $25 \pm 2{ }^{\circ} \mathrm{C}$ without shaking. Experiments with fungal cultures were repeated three times unless otherwise noted, with three replicates per treatment in each experiment.

Induction and detection of cutinase and PG. Cutinase activity was routinely determined by measuring PNB hydrolysis according to published methods (6). The kinetics of PNB hydrolysis activity was determined at $405 \mathrm{~nm}$ in a 96-well plate with a SpectraMax 340 spectrophotometer and SOFTmax PRO software (Molecular Devices Corp., Sunnyvale, CA) in the kinetic preference mode. Data were collected over time with 28 readings per sample taken within $5 \mathrm{~min}$. Under the kinetic preference mode with Vmax for data display, neither $1 \mathrm{mM} \mathrm{CA}$ nor the autoclaved culture filtrates interfered with the detection of PNB hydrolysis activity. The kinetics of PNB hydrolysis as a measure of cutinase activity is reported as the change in milliA $_{405} / \mathrm{min}$ when $10 \mu \mathrm{l}$ of culture filtrate was used in the reaction mixture.

PG activity was determined by measuring the production of reducing sugars (17). Boiled filtrates $\left(100^{\circ} \mathrm{C}\right.$ for $\left.10 \mathrm{~min}\right)$ were used as controls. The net PG activity of a sample was obtained after subtracting the reading of the boiled sample to eliminate any potentially interfering effects of $\mathrm{CA}$ or its metabolites on the determination of enzyme activity.

Determination of fungal dry weight, redox potentials, and pH. To determine dry weight of mycelia, filter paper disks (Whatman No.1) were dried in an oven at $100^{\circ} \mathrm{C}$ for $24 \mathrm{~h}$ and then placed in a desiccator under vacuum to cool. After the dry weight of each paper was determined, mycelia from each flask were collected by filtration onto the paper and washed with $50 \mathrm{ml}$ of deionized water. The filter papers with mycelia were then placed in an oven to dry and weighed under the same conditions as above, and the mycelial dry weights were calculated.

For intracellular GSH determinations, mycelia were collected by filtration and placed into liquid nitrogen immediately. Aliquots from culture filtrates were used for determination of extracellular cutinase and PG activities, absolute electrochemical (redox) potential, and $\mathrm{pH}$. Redox potential and $\mathrm{pH}$ of the filtrates were measured with a platinum $\mathrm{Ag} / \mathrm{AgCl}$ combination electrode and a $\mathrm{pH}$ electrode, respectively, with an Accumet AR20 meter (Fisher Scientific). Zobell's solution (potassium ferro-ferricyanide solution; Fisher) was used for instrument standardization for redox measurements. For enzyme assays, the filtrates were kept on ice or stored at $-20^{\circ} \mathrm{C}$.

Measurement of intracellular GSH and GSSG contents. Total GSH was determined as described by Tietze (46) with modifications. The assay is based on the recycling of total GSH by DTNB and GSH reductase. GSH is oxidized by DTNB to give GSSG with stoichiometric formation of 5-thio-2-nitrobenzoic acid (TNB), while GSSG is reduced to GSH by the highly specific GSH reductase. The rate of TNB formation is followed at $405 \mathrm{~nm}$ and is proportional to the sum of GSH and GSSG present.

Mycelia were ground into fine powder in liquid nitrogen, transferred into liquid nitrogen-cooled tubes, and placed in a container with dry ice until all samples were prepared. One milliliter of extraction buffer of $20 \mathrm{mM}$ sodium phosphate buffer $(\mathrm{pH}$ 7.4) was added per $100 \mathrm{mg}$ of mycelia and vortexed briefly. The extracts were centrifuged at $20,000 \times g$ for $30 \mathrm{~min}$ at $4^{\circ} \mathrm{C}$, and the supernatants were mixed with $10 \% 5$-sulfosalicylic acid solution $(2: 1, \mathrm{vol} / \mathrm{vol})$ to precipitate protein and centrifuged again at $20,000 \times g$ for $5 \mathrm{~min}$ at $4^{\circ} \mathrm{C}$. The resulting supernatant was collected for $\mathrm{GSH}$ detection using a 96-well microtiter plate format with three replicates per sample. Each reaction mixture contained $50 \mu \mathrm{l}$ of sample solution or standard solution, $175 \mu \mathrm{l}$ of $0.3 \mathrm{mM}$ NADPH, and $25 \mu \mathrm{l}$ of $6 \mathrm{mM}$ DTNB, and the mixture was incubated at $30^{\circ} \mathrm{C}$ for $30 \mathrm{~min}$. The rate of TNB formation was 
determined at $405 \mathrm{~nm}$ with a SpectraMax 340 spectrophotometer and SOFTmax PRO software in the kinetic preference mode. The data were collected over time with 20 readings taken within 4 min. Reduced GSH (0 to $50 \mu \mathrm{M}$ in twofold serial dilutions) was used to create a standard calibration curve. The data were recorded after adding $5 \mu \mathrm{l}$ of GSH reductase ( 75 units $/ \mathrm{ml}$ of buffer) to start the reaction and incubating at $30^{\circ} \mathrm{C}$ for $5 \mathrm{~min}$. Using the kinetic preference mode with Vmax for data display, CA did not interfere with GSH determinations.

Appressorium formation. $M$. fructicola conidia were harvested from V8 juice agar plates and washed as described previously (25). Macroconidia of M. fructicola were collected from 7- to 10-day-old V8 juice agar plates by flooding with sterile water. Conidial suspensions were filtered through one layer of Miracloth to remove mycelia and washed twice with sterile water by centrifugation at $10,600 \times g$ for $30 \mathrm{~s}$. The washed or unwashed conidia were diluted to $5 \times 10^{5}$ conidia/ml unless otherwise noted and mixed with other components as appropriate for assessment of appressorial formation. Appressorial formation was determined by placing a 5 - $\mu$ l drop of the conidial suspension with $1 \mathrm{mM}$ sucrose on a polystyrene petri dish lid (Fisher Scientific) and incubating in a moist chamber at $25 \pm 2{ }^{\circ} \mathrm{C}$, unless indicated otherwise. A $0.4 \%$ aliquot of methanol and water were used as controls in treatments involving CA and CGA, and reduced GSH, respectively.

Inoculation of flower petals and fruit. Inoculations of flower petals and fruit were performed as described previously (25). CA, CGA, or reduced GSH was mixed with the conidial suspension prior to inoculation, and $0.4 \%$ methanol was added as a control treatment. Flower petals from almond, nectarine, and peach blossoms collected from UC Davis experimental orchards were placed in a moist chamber. Each inoculation site received $5 \mu \mathrm{l}$ of the conidial suspension $\left(5 \times 10^{4}\right.$ conidia/ml $)$ or conidial suspension containing a test compound. Development of brown rot symptoms on petals was recorded with a digital camera and the size of the resulting lesion was estimated using Spot Image Analysis software (Spot RT Software version 3.5.1, Diagnostic Instruments, Sterling Heights, MI).

Determination of total phenols and CGA in peach fruit peel extracts. Developmental stages of fruit were classified based on fruit size and embryo development following the criteria described in Zucconi (50) and in our recent paper (25). Fruit stages were determined by measuring the diameters of representative fruit and assessing embryo development by splitting the pit and embryo with a knife. Stage I fruit have a diameter less than $2.8 \mathrm{~cm}$ and embryos and pits that are readily split. Stage II fruit have a diameter between 2.8 and $3.3 \mathrm{~cm}$ and a hardened endocarp (pit and embryo not cleaved with a knife). Stage III fruit have a diameter greater than $3.3 \mathrm{~cm}$. In the present study, chemical analyses were conducted on stage II and stage III fruit. Tissue cores of 12 to $15 \mathrm{~mm}$ in diameter were obtained from fruit of different developmental stages with a cork borer, and the peel was separated from the underlying mesocarp tissue with a razor blade. The resulting tissue pieces were largely comprised of exocarp (cuticle, epidermis, and hypodermis) with a small amount of subtending mesocarp. For each sample, five peel disks were placed in a screw cap test tube containing $5 \mathrm{ml}$ of acidified $(0.01 \mathrm{~N} \mathrm{HCl})$ methanol. For high-performance liquid chromatography (HPLC) determinations of CGA, $200 \mu \mathrm{g}$ of gentisic acid also was added to each sample to provide an internal standard. The tissue was thoroughly homogenized for 5 to $10 \mathrm{~s}$ in the test tube, using a Polytron tissue homogenizer (Brinkmann Instruments, Westbury, NY), and the extracts were sealed with Teflon-lined screw caps and placed in an oven at $60^{\circ} \mathrm{C}$ overnight. After cooling, the extracts were adjusted to their original volume with acidified methanol as necessary and mixed. One milliliter of the extract was centrifuged at $14,000 \mathrm{rpm}$ for $15 \mathrm{~min}$ and the supernatant was passed through a $0.45 \mu \mathrm{m}$ nylon filter for HPLC analysis. For each genotype analyzed, one sample was prepared from each of five fruit.

Total reducing phenols in extracts (without added gentisic acid) were determined by the Folin-Ciocalteu procedure (43). Briefly, $0.2 \mathrm{ml}$ of a 10-fold dilution with water of the extract was mixed with $1 \mathrm{ml}$ of Folin-Ciocalteu's phenol reagent (Sigma F-9252) and $0.8 \mathrm{ml}$ of sodium carbonate $(7.5 \%)$. The reaction mixture was incubated at $25 \pm 2{ }^{\circ} \mathrm{C}$ for $30 \mathrm{~min}$, and the absorbance at $725 \mathrm{~nm}$ was measured on a spectrophotometer. Gallic acid $(500 \mu \mathrm{g} / \mathrm{ml})$ in twofold serial dilutions in water was used to generate a standard curve. The content of total phenols in fruit peel was expressed as gallic acid equivalents in milligrams (or micrograms) per gram fresh weight of tissue.

HPLC analysis. CGA content was measured by an HPLC procedure developed for quantitation of peach fruit phenolic acids, which is modified from a procedure developed for analysis of wine polyphenols by Singleton and Trousdale (44). A 10- $\mu 1$ aliquot of the filtered extract was injected onto a Varian 5000 series HPLC (Varian Inc., Palo Alto, CA). Phenolic compounds were separated on a Microsorb-MV C18 column (4.6 $\mathrm{mm}$ in diameter by $15 \mathrm{~cm}$; Rainin Instrument Co., Woburn, MA) and detected with a UV monitor set at $280 \mathrm{~nm}$. For the mobile phases, $0.05 \mathrm{M} \mathrm{NH}_{4} \mathrm{HPO}_{4}$ in water, $\mathrm{pH} 2.6(4.9 \mathrm{ml}$ of o-phosphoric acid/liter adjusted to $\mathrm{pH} 2.6$ with $\mathrm{NH}_{4} \mathrm{OH}$; solvent $\mathrm{A}$ ), and $20 \%$ solvent $\mathrm{A} / 80 \%$ acetonitrile (solvent $\mathrm{B}$ ) were used. The gradient profile consisted of $100 \%$ A for $2 \mathrm{~min}, 15 \%$ B for $10 \mathrm{~min}, 23 \% \mathrm{~B}$ for $13 \mathrm{~min}, 63 \% \mathrm{~B}$ for $15 \mathrm{~min}$, and $100 \% \mathrm{~B}$ for $5 \mathrm{~min}$. Flow rate was maintained at $0.6 \mathrm{ml} / \mathrm{min}$ for $30 \mathrm{~min}$ followed by $5 \mathrm{~min}$ at $1.0 \mathrm{ml} / \mathrm{min}$. CGA concentrations in sample extracts were determined by peak integration and comparison with a standard mixture that included gentisic acid.

Analysis of experimental data. All experiments were conducted at least twice with at least three replicates of each treatment within each experiment, except as noted otherwise. The significance of treatments was determined by using paired $t$ test, regression analysis, and analysis of variance (ANOVA) with Dunnett's tests as implemented in PC-SAS (SAS Institute, Cary, NC).

\section{RESULTS}

Peach peel CGA content declines during fruit maturation. The total reducing phenol contents of the peels from fruit of intermediate maturity (stage II) and harvest maturity (late stage III) were determined. Fruit obtained from a line used in the UC Davis cling peach breeding program were used for these analyses. The stage II fruit peels had $1.57 \pm 0.33 \mathrm{mg}$ of gallic acid equivalents per gram fresh weight, a significantly higher phenolic content than late stage III fruit peels, which had $0.74 \pm 0.17 \mathrm{mg}$ gallic acid equivalents per gram fresh weight ( $t$ test with unequal variance; $P<0.01)$. In earlier experiments using HPLC analyses, CGA was identified as a major phenolic acid in peach peels that declined during the transition from stage II to stage III fruits (Fig. 1). This was observed in three different peach genotypes, cv. Bolinha, cv. Corona, and breeding line 18-8-11. Peels from stage II fruit (sampled on 16 July 1993) had significantly higher CGA levels than peels from late stage III fruit (sampled on 30 August 1993) (two-way ANOVA; $P<0.05$ ) (Fig. 1). In some samples from stage II fruit, CGA concentrations were as high as $1 \mathrm{mg} / \mathrm{g}$ fresh weight, approximately equivalent to $2.8 \mathrm{mM}$. CGA concentrations decreased during stage III to a low level at harvest maturity in the three tested genotypes (all $\leq 70 \mu \mathrm{g} \mathrm{g} \mathrm{g}^{-1}$ fresh weight). Although CGA was the most abundant phenolic acid detected in our analyses, other significant peach peel phenols included catechin, epicatechin, and CA. These also showed a marked decline in concentration in peels from fruit at harvest maturity relative to less mature fruit (data not shown).

CA inhibits $M$. fructicola PG production. CA and CGA inhibit cutinase production by $M$. fructicola in cutinase-induction 
medium (6). To determine if CA also affects PG, a cell wall degrading activity produced by $M$. fructicola, $1 \mathrm{mM}$ CA was incorporated in the PG-induction medium and the enzyme activity in culture filtrates was monitored. PG activity was detected in M. fructicola culture filtrates 3 days postinoculation (dpi) and increased thereafter (Fig. 2). PG activity was significantly reduced in cultures containing CA $(P<0.01$ using a paired $t$ test). There was no significant effect of CA on mycelial growth in these cultures relative to the control $(P=0.2$ at $13 \mathrm{dpi}$ using a paired $t$ test).

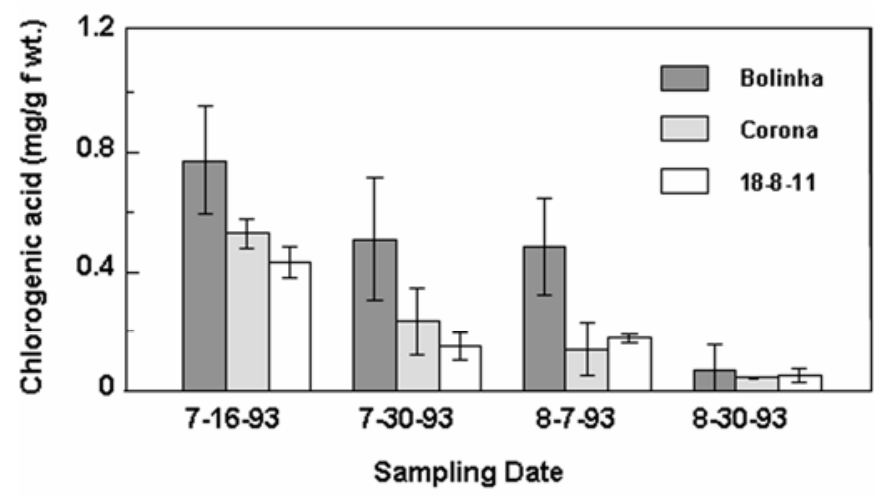

Fig. 1. Chlorogenic acid (CGA) content of peach exocarp tissue from different developmental stage fruits. Peach genotypes analyzed were the South American cv. Bolinha, a breeding line 18-8-11, and the commercial cv. Corona. Fruit selected for analyses were all of similar maturity for each developmental stage. CGA was determined by high-performance liquid chromatography and each value is the mean and standard error of three to six samples, with each sample from a separate fruit. Fruit of intermediate maturity (late developmental stage II) were harvested on 16 July 1993. Fruit collected on 30 August 1993 were of commercial harvest maturity (late developmental stage III).
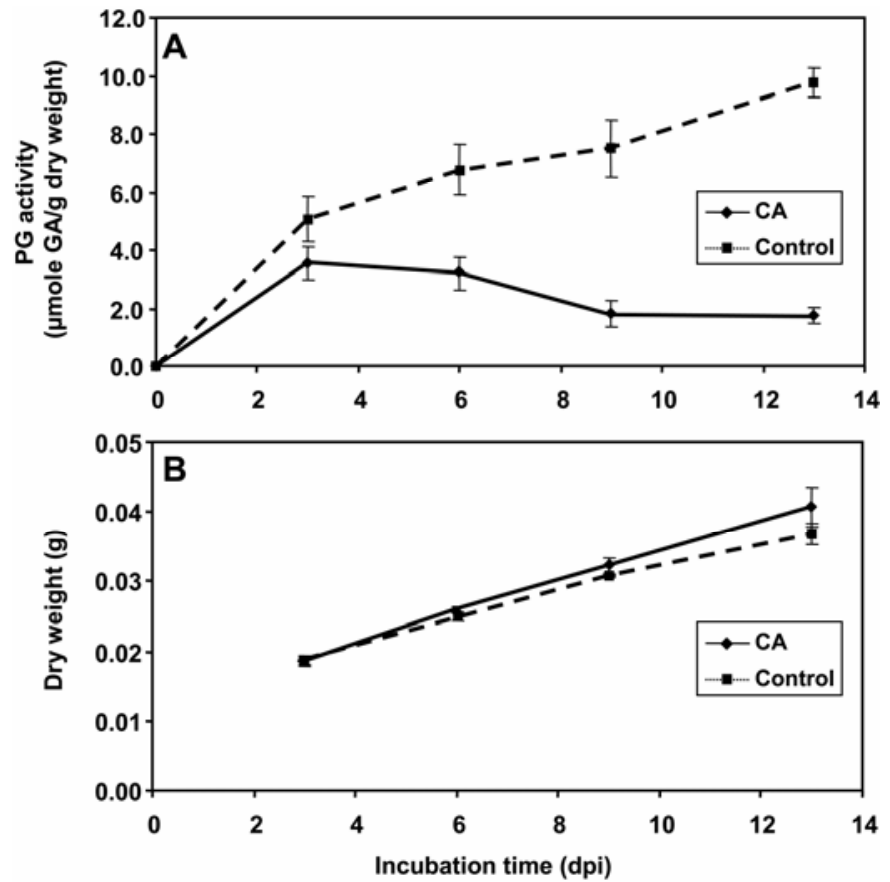

Fig. 2. The effect of $1 \mathrm{mM}$ caffeic acid (CA) on Monilinia fructicola polygalacturonase (PG) production. Specific activity of PG expressed as $\mu$ mole galacturonic acid (GA) per gram dry weight mycelium. Data are from a single trial representative of at least two trials. Each value is the mean and standard deviation of three samples from three separate culture flasks. A paired $t$ test was used to analyze the difference between CA and control treatment at each sampling point. CA significantly inhibited PG production at 6,9 , and 13 days postinoculation $(P<0.01)$, whereas it did not have a significant effect on fungal growth (mycelial dry weight) at any sampling day $(P>0.05$; data not shown).
Inhibition of cutinase and PG production by $M$. fructicola by $\mathbf{C A}$ is redox-related. The electrochemical redox potential of culture filtrates was directly measured with a redox electrode. As shown in Figure 3, the redox potentials in M. fructicola cultures decreased during the first 3 days of incubation, regardless of the carbon source provided in the medium, including mCZ-glucose, $\mathrm{mCZ}$-cutin, and $\mathrm{mCZ}$-polygalacturonate. The addition of CA to cultures resulted in a rapid 15 to $25 \%$ reduction in the electrochemical redox potential in all three media. The results indicate that treatment of the cultures with CA creates an extracellular reducing environment relative to the control.

The intracellular redox status of mycelia was determined indirectly by measurement of total GSH. The results showed that intracellular GSH contents increased significantly in $1 \mathrm{mM} \mathrm{CA}$ treatment at 12 or 13 days after inoculation in all three media (data for mCZ-cutin and $\mathrm{mCZ}$-polygalacturonate are presented in Figure 4). CA significantly inhibited cutinase activity in culture filtrates but increased intracellular total GSH content on the cutinase-induction medium (Fig. 4A). In PG-induction medium, CA also significantly increased total GSH and inhibited PG production (Figs. 2 and 4B). However, the time course of inhibition of PG by CA lagged behind that for cutinase and did not appear to be as tightly regulated by the change in the redox potential of the cultures induced by $\mathrm{CA}$. Nonetheless, the CA effect on GSH content was apparent in both short (4 to 6 days) and long (12 to 13 days) incubations. There was no significant

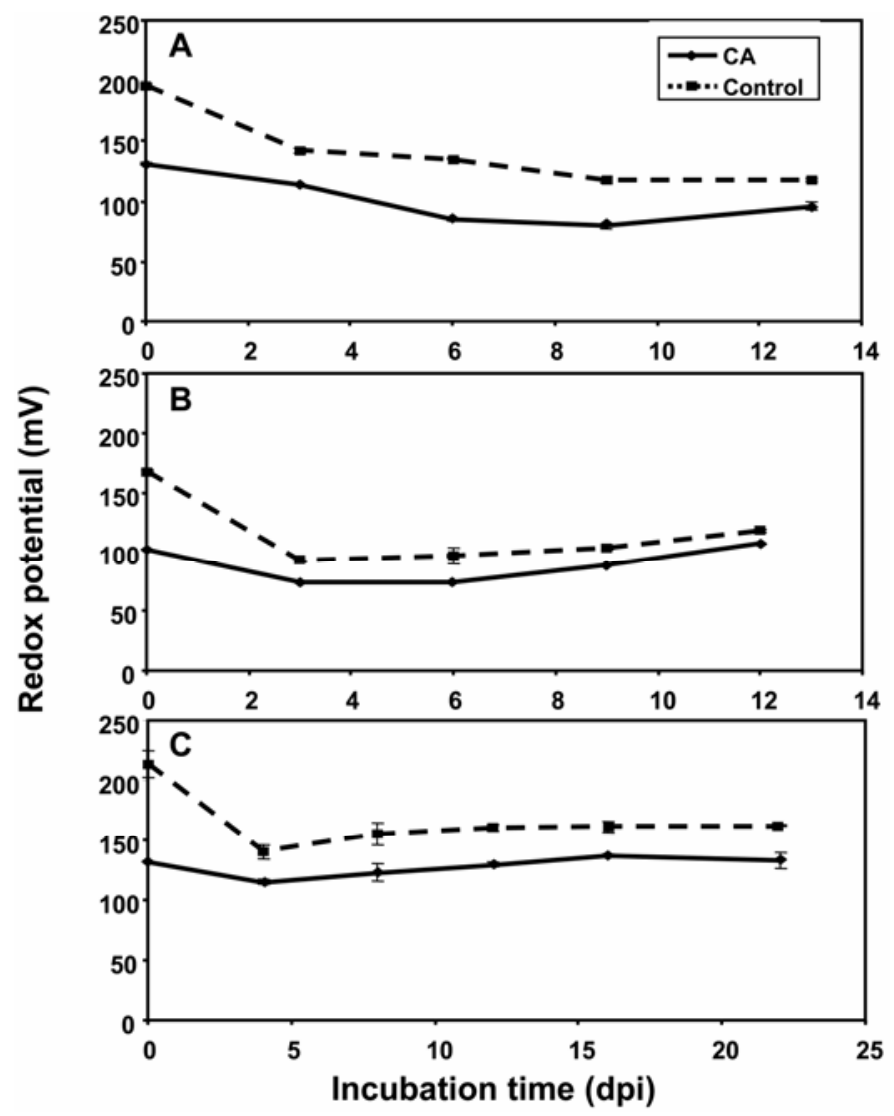

Fig. 3. Electrochemical redox potential in Monilinia fructicola cultures in three different media with or without caffeic acid (CA). A, mCZ-polygalacturonate, PG-induction medium; B, mCZ-glucose medium; and $\mathbf{C}, \mathrm{mCZ}$ cutin, cutinase-induction medium. $M$. fructicola was grown in each medium in the presence of $1 \mathrm{mM} \mathrm{CA}$ or $0.4 \%$ methanol carrier (control). Data are from a single trial representative of at least two trials. Each value is the mean and standard deviation of three culture filtrate samples from three separate culture flasks, as determined with a redox electrode. A paired $t$ test was used to analyze the difference between the $\mathrm{CA}$ and control treatments at each sampling point. CA significantly reduced the electrochemical redox potential of the medium at all sampling dates in the three media tested $(P<0.05)$. 
difference in $\mathrm{pH}$ between the CA-treated culture and the control (data not shown).

Antioxidants inhibit appressorium formation in $M$. fructicola. Washed conidial suspensions of M. fructicola were treated with various concentrations of CGA and CA to determine if these compounds affected germination and appressorium formation. Conidial germination and appressorium formation from the germinated conidia were determined by microscopy. CA did not affect conidial germination and appressorium formation at concentrations up to $0.5 \mathrm{mM}$, measured after $6 \mathrm{~h}$ incubation (Fig. 5A; Table 1). CA at $1 \mathrm{mM}$ inhibited both conidial germination $(30 \%)$ and appressorium formation $(50 \%)$. CGA was a more potent inhibitor of germination and appressorium formation than CA, with significant inhibition of germination $(>20 \%)$ and appressorium formation $(>70 \%)$ at concentrations $\geq 0.5 \mathrm{mM}$ (Fig. $5 \mathrm{~B}$; Table 1). Both CA and CGA at $1 \mathrm{mM}$ inhibited germ tube elongation when examined after $16 \mathrm{~h}$ incubation. Since CA significantly reduced the redox potential of the medium and increased pool sizes of intracellular GSH in $M$. fructicola, the possible effect of externally applied reduced GSH on germination and appressorium formation was examined (Fig. 5C; Table 1). Similar to CGA and $\mathrm{CA}$, GSH did not affect germination at the low concentration
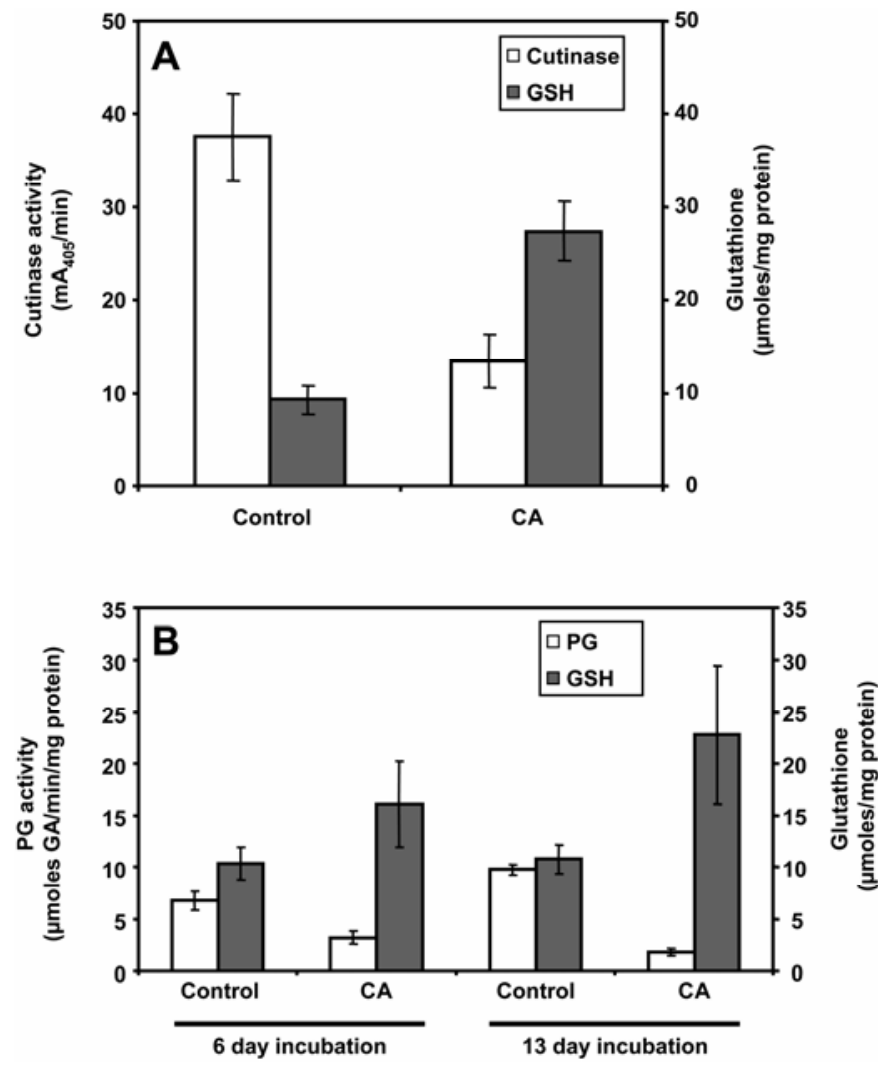

Fig. 4. Intracellular total glutathione (GSH) in Monilinia fructicola is increased by caffeic acid (CA). A, M. fructicola was grown in cutinaseinduction medium for 15 days. Cutinase activity $\left(\mathrm{milliA}_{405} / \mathrm{min} / 10 \mu \mathrm{l}\right.$ culture filtrate) and GSH content ( $\mu$ mole GSH per milligram of protein) were determined in culture filtrates and in mycelia, respectively. B, M. fructicola was grown in polygalacturonase (PG)-induction medium for 6 and 13 days. GSH content was detected in mycelia, while the corresponding PG activity for the indicated sampling day was determined from the culture filtrate. Results are from a single trial representative of at least two trials. Each value is the mean and standard deviation of three samples each from a separate culture flask. A, A $t$ test for unequal variance showed that $1 \mathrm{mM} \mathrm{CA}$ significantly inhibited cutinase production and increased intracellular GSH content on cutinase-induction medium $(P<0.05)$. B, Two-way analysis of variance showed that $1 \mathrm{mM} \mathrm{CA}$ significantly increased intracellular GSH content on PG-induction medium $(P<0.05)$. However, length of incubation period did not have a significant effect on GSH content in $M$. fructicola grown on the PG-induction medium $(P=0.2)$. tested $(0.1 \mathrm{mM})$. GSH at external concentrations $\geq 0.5 \mathrm{mM}$ slightly reduced germination, but markedly inhibited appressorium formation by $70 \%$ (Fig. 5C), suggesting that cellular redox status could play an important role in the development of appressoria.

Antioxidants inhibit symptom development of brown rot disease. Prunus petals and cherry fruits were inoculated with
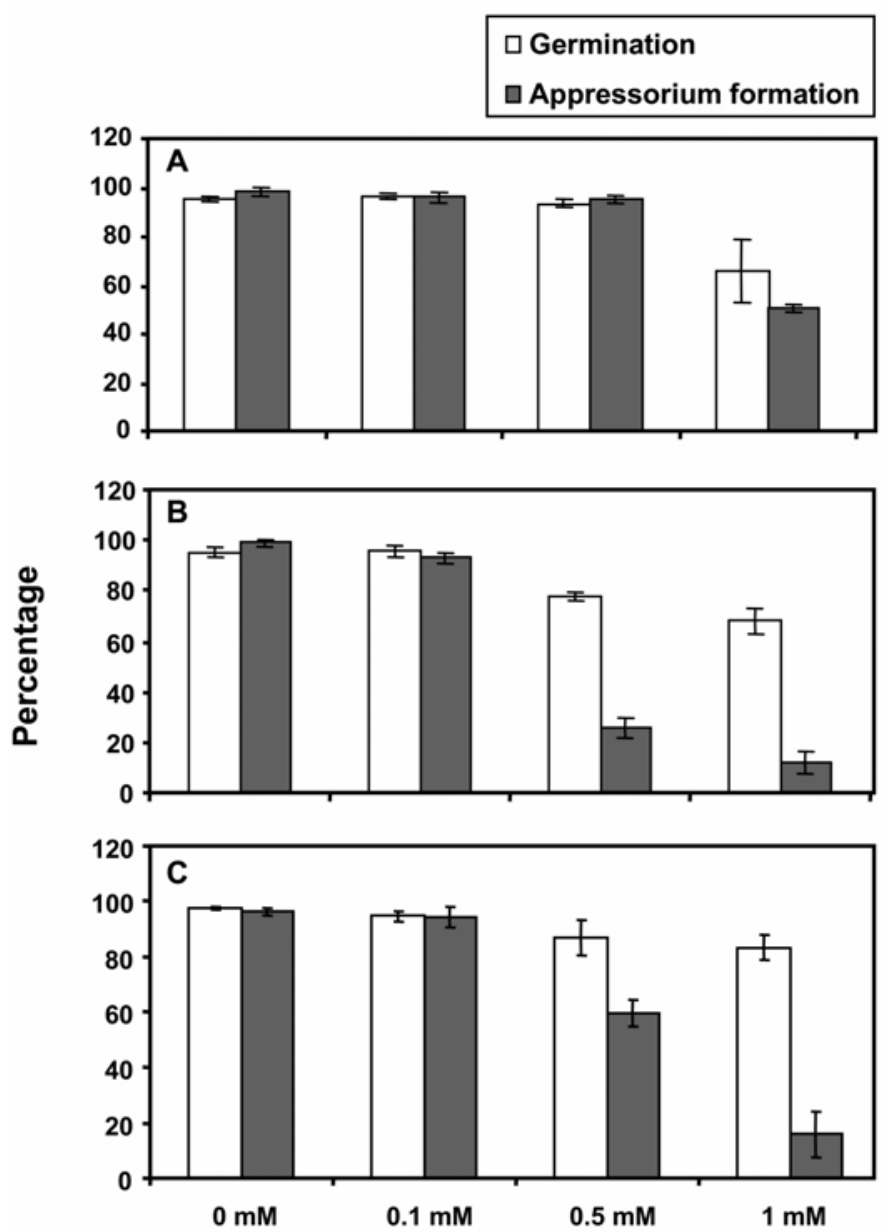

Fig. 5. The effect of antioxidants on Monilinia fructicola conidial germination and appressorium formation: A, caffeic acid (CA), B, chlorogenic acid (CGA), and $\mathbf{C}$, reduced glutathione (GSH). Data are from a single experiment representative of at least two experiments. Each value is the mean and standard deviation of three separate samples. Regression analysis of the untransformed data for response to CA, CGA, and GSH showed that they significantly inhibited germination $\left(\mathrm{CA}\right.$, slope $=-29 \% / \mathrm{mM}, P<0.0001, R^{2}=$ $0.90 ;$ CGA, slope $=-29 \% / \mathrm{mM}, P<0.0001, R^{2}=0.90 ;$ and GSH, slope $=$ $\left.-14 \% / \mathrm{mM}, P=0.0004, R^{2}=0.73\right)$ and appressorium formation $(\mathrm{CA}$, slope $=$ $-92 \% / \mathrm{mM}, P<0.0001, R^{2}=0.89 ;$ CGA, slope $=-93 \% / \mathrm{mM}, P<0.0001$, $R^{2}=0.89 ;$ and GSH, slope $\left.=-82 \% / \mathrm{mM}, P<0.0001, R^{2}=0.98\right)$.

TABLE 1. Statistical analysis of the effect of caffeic acid (CA), chlorogenic acid (CGA), and reduced glutathione (GSH) on conidial germination (G) and subsequent appressorium formation (A) from washed conidia of Monilinia fructicola

\begin{tabular}{|c|c|c|c|c|c|c|}
\hline \multirow[b]{3}{*}{ Concentration } & \multicolumn{6}{|c|}{$P$ value $^{\mathrm{a}}$} \\
\hline & \multicolumn{2}{|c|}{ CA } & \multicolumn{2}{|c|}{ CGA } & \multicolumn{2}{|c|}{ GSH } \\
\hline & G & A & G & A & G & A \\
\hline $0.1 \mathrm{mM}$ & 1.0 & 0.9 & 1.0 & $<0.05$ & 0.7 & 0.9 \\
\hline $0.5 \mathrm{mM}$ & 0.9 & 0.9 & $<0.05$ & $<0.05$ & $<0.05$ & $<0.05$ \\
\hline $1 \mathrm{mM}$ & $<0.05$ & $<0.05$ & $<0.05$ & $<0.05$ & $<0.05$ & $<0.05$ \\
\hline
\end{tabular}

a $P$ values were determined by a one-way analysis of variance followed by a Dunnett's test to compare the treatment with a nonamended control. 
M. fructicola with or without the supplement of CGA, CA, or GSH to determine if these compounds could influence the development of brown rot lesions. Lesion size and disease incidence (number of petals infected) were significantly reduced $(P<$ $0.001)$ when the infection droplets contained any of the three antioxidants at $0.5 \mathrm{mM}$ (Table 2; Fig. 6). Lesions progressed slowly in the presence of the test compounds compared with the controls. Symptoms were apparent in 30 to $50 \%$ of the control petals within $12 \mathrm{~h}$ postinoculation (hpi), while no symptoms were observed on petals treated with any of the test compounds (Table 2; Fig. 6). At $30 \mathrm{hpi}, 83$ to $93 \%$ of the inoculated petals in the control displayed necrotic lesions, whereas only 17 to $30 \%$ of the inoculated areas treated with the antioxidants had visible lesions (Table 2). Upon examination of the inoculated petals under the microscope, conidia in the control treatment germinated and formed appressoria. In contrast, conidia inoculated with CA, CGA, or GSH germinated and formed long germ tubes, but only a few of the germinated conidia produced appressoria (data not shown). CA, CGA, and GSH also reduced symptom development in a concentration-dependent manner (Table 3). CA, CGA, and GSH at $1 \mathrm{mM}$ completely inhibited lesion development, although this is a concentration where these compounds also partially inhibit germination and growth. A similar inhibition by these compounds was observed when tested at $1 \mathrm{mM}$ in all experiments, which included nectarine cvs. Flavor Top and Fantasia and peach cvs. Carson and Loadel. The test compounds at $1 \mathrm{mM}$ also markedly reduced lesion size and disease incidence on cherry cvs. Bing and Rainier (Table 4).

\section{DISCUSSION}

Significant changes in volatiles, organic acids, phenolic compounds, and cell wall composition occur during development of Prunus fruit concomitant with changes in susceptibility to brown rot $(5,8,10,11,20,26,42)$. Our study shows that the levels of total phenols in fruit peels (predominantly exocarp) are much higher in immature (stage II) fruit but are significantly lower in fruit of harvest maturity (late stage III). CGA is a major phenolic acid in peach peels that declines during the transition from stage II to stage III fruits. Similar observations also have been made on the mesocarp (flesh) of two Japanese peach cultivars (23). Early studies of apple brown rot caused by Sclerotinia fructigena (syn. M. fructigena) also indicated a strong correlation between the polyphenolic content and disease resistance in various apple cultivars $(9,15)$. Previous research in our laboratory demonstrated that plant phenols from fruit peel strongly inhibited the expression of the Mfcutl gene encoding a cutinase without inhibiting fungal growth in vitro (6). Although multiple mechanisms likely contribute to the increase in fruit disease susceptibility during maturation, the present study provides a more comprehensive analysis of the effect of fruit phenols on processes associated with $M$. fructicola infection and lesion development.

TABLE 2. Reduction of brown rot lesion development by caffeic acid (CA), chlorogenic acid (CGA), and reduced glutathione (GSH) on peach petals after inoculation with Monilinia fructicola ${ }^{\text {a }}$

\begin{tabular}{|c|c|c|c|c|c|c|c|c|c|}
\hline \multirow[b]{2}{*}{$\mathrm{hpi}^{\mathrm{c}}$} & \multicolumn{2}{|c|}{$\begin{array}{l}\text { Mean lesion area }\left(\mathrm{mm}^{2}\right)^{\mathrm{b}} \\
\text { (no. of petals with lesions) }\end{array}$} & \multirow{2}{*}{$\begin{array}{l}\text { \% Reduction } \\
\text { of infected } \\
\text { area by CA }\end{array}$} & \multicolumn{2}{|c|}{$\begin{array}{l}\text { Mean lesion area }\left(\mathrm{mm}^{2}\right)^{\mathrm{b}} \\
\text { (no. of petals with lesions) }\end{array}$} & \multirow{2}{*}{$\begin{array}{l}\% \text { Reduction } \\
\text { of infected } \\
\text { area by CGA }\end{array}$} & \multicolumn{2}{|c|}{$\begin{array}{l}\text { Mean lesion area }\left(\mathrm{mm}^{2}\right)^{\mathrm{b}} \\
\text { (no. of petals with lesions) }\end{array}$} & \multirow{2}{*}{$\begin{array}{l}\% \text { Reduction } \\
\text { of infected } \\
\text { area by GSH }\end{array}$} \\
\hline & Control & $\mathrm{CA}$ & & Control & CGA & & Control & GSH & \\
\hline 12 & $3.4(15)$ & $0.0(0)$ & 100 & $2.0(10)$ & $0.0(0)$ & 100 & $2.2(9)$ & $0.0(0)$ & 100 \\
\hline
\end{tabular}

${ }^{a}$ Reagents $(0.5 \mathrm{mM})$ were mixed with 250 conidia and applied in a 5 - $\mu$ d droplet on one side of each petal. The other side was inoculated with the same inoculum concentration in $0.4 \%$ methanol carrier as a control. Data are from one experiment and the experiment was repeated at least once with each test compound with similar results. Flower petals were obtained from blossoms collected from peach trees (cv. Loadel) from a UC Davis experimental orchard.

${ }^{\mathrm{b}}$ Statistical analyses were done by paired $t$ test of actual lesion areas of 30 inoculated petals. All reagents significantly reduced lesion sizes compared with the control even after $30 \mathrm{hpi}(P<0.001)$.

${ }^{\mathrm{c}}$ Mean lesion sizes and numbers of infected petals from 30 petals for each treatment were recorded 12 and $30 \mathrm{~h}$ postinoculation (hpi).

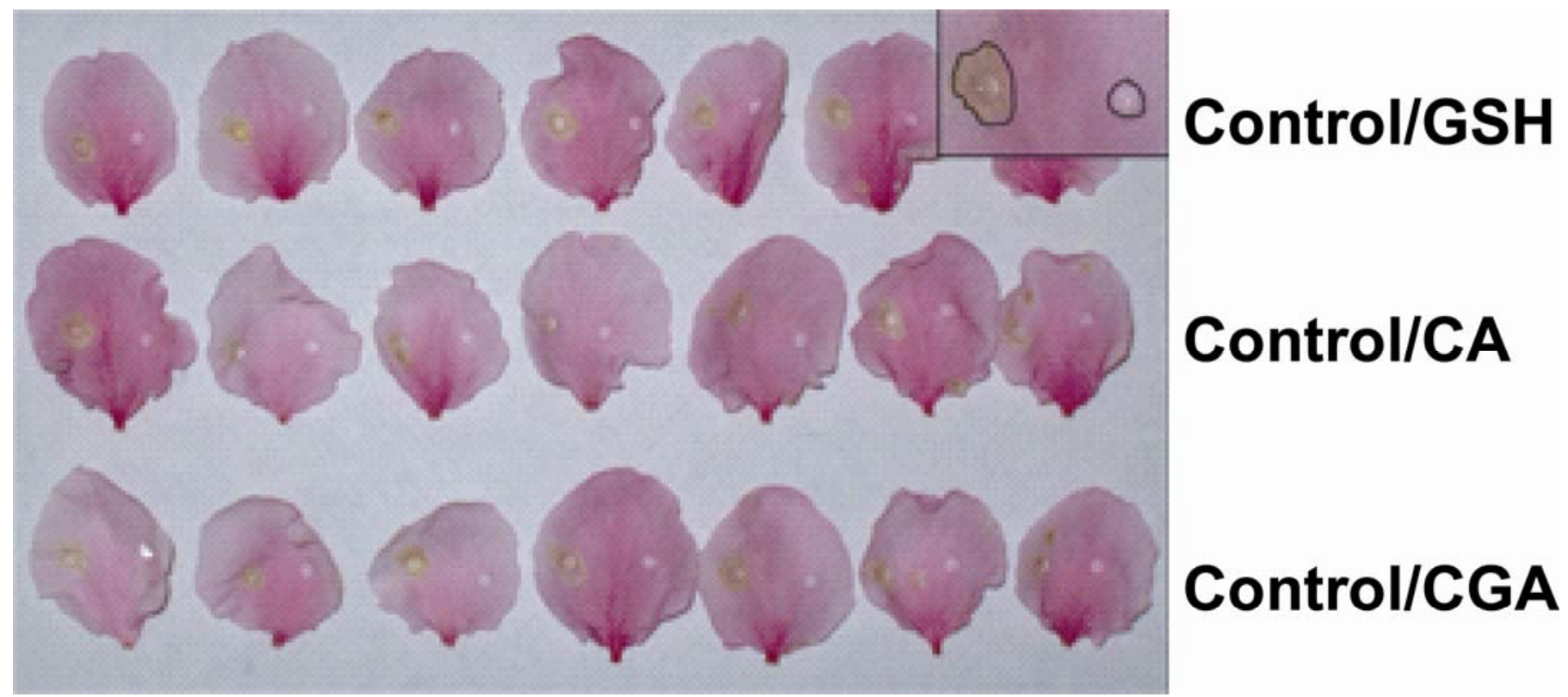

Fig. 6. Brown rot lesion sizes on peach cv. Loadel petals are inhibited by $0.5 \mathrm{mM}$ caffeic acid (CA), chlorogenic acid (CGA), and reduced glutathione (GSH) at $12 \mathrm{~h}$ postinoculation. The insert shows a close-up image of a paired inoculation with control (left) or antioxidant-treated (right) conidia of Monilinia fructicola on a petal. The lesion areas were digitally marked for imaging and measurement using Spot Image Analysis software (Diagnostic Instruments, Sterling Heights, MI). Numerical data are presented in Tables 2 and 3. 
The involvement of cell wall degrading enzymes in pathogenesis is strongly suggested by the maceration of host tissue during colonization by $M$. fructicola. Furthermore, Mfpgl, which is a PG gene of $M$. fructicola, is expressed during infection of Prunus flower petals and apple fruit (M.-H. Lee and R. M. Bostock, unpublished data). Here we show that CA inhibits the production of PG by $M$. fructicola at concentrations where there is no inhibition of fungal growth and at concentrations that are within the physiological range that occurs in fruit peels (Fig. 1) (6). The inhibition of PG production in M. fructicola by CA is similar to the effect of this compound on cutinase production (6), and thus could also be at the level of gene expression.

Plant phenolics, including $\mathrm{CA}$ and $\mathrm{CGA}$, have received considerable attention in medicine and food science as potential dietary antioxidants for prevention of cancer and other diseases $(29,41,49)$. CA and CGA reduce activator protein-1 (AP-1)regulated transcription in cells exposed to carcinogens $(16,27)$. AP-1 is a transcription factor that is sensitive to changes in cellular redox potential (4), and is important in eukaryotes for its involvement in several signal transduction pathways, notably in the coupling of responses for oxidative stress management and metal tolerance in mammalian and yeast cells $(3,32)$. When cells experience oxidative stress, redox signaling cascades may occur to affect gene expression. Activation of AP-1 in cells undergoing such stresses can result in the expression of target genes having the appropriate AP-1 binding domains in their promoters (4). Analysis of the Mfcutl and Mfpgl promoters identified multiple potential binding domains that could recognize AP-1 (24). Thus, it is tempting to speculate that an analogous mechanism, mediated

TABLE 3. The concentration-dependent effect of caffeic acid (CA) and reduced glutathione $(\mathrm{GSH})$ on the reduction of brown rot lesion development in peach flower petals ${ }^{\mathrm{a}}$

\begin{tabular}{|c|c|c|c|c|c|}
\hline \multirow[b]{2}{*}{ Reagent } & \multirow[b]{2}{*}{ Concentration } & \multicolumn{2}{|c|}{$\begin{array}{c}\text { Mean lesion area }\left(\mathrm{mm}^{2}\right) \\
\text { (no. of petals with } \\
\text { lesions) }\end{array}$} & \multirow{2}{*}{$\begin{array}{c}\text { Paired } \\
t \text { test } \mathrm{t}^{\mathrm{b}} \\
(P \text { values })\end{array}$} & \multirow{2}{*}{$\begin{array}{l}\% \text { Reduction } \\
\text { of infected } \\
\text { area }\end{array}$} \\
\hline & & Control & Treatment & & \\
\hline \multirow[t]{3}{*}{$\mathrm{CA}$} & $0.25 \mathrm{mM}$ & $22.6(10)$ & $12.8(4)$ & $<0.01$ & 44 \\
\hline & $0.5 \mathrm{mM}$ & $18.6(10)$ & $0.0(0)$ & $<0.0001$ & 100 \\
\hline & $1 \mathrm{mM}$ & $15.9(9)$ & $0.0(0)$ & $<0.001$ & 100 \\
\hline \multirow[t]{3}{*}{ GSH } & $0.25 \mathrm{mM}$ & $18.8(10)$ & $7.8(6)$ & $<0.001$ & 68 \\
\hline & $0.5 \mathrm{mM}$ & $16.2(9)$ & $2.6(4)$ & $<0.001$ & 84 \\
\hline & $1 \mathrm{mM}$ & $18.9(10)$ & $0.0(0)$ & $<0.0001$ & 100 \\
\hline
\end{tabular}

a Reagents at the concentrations indicated were mixed with a conidial suspension (125 spores for CA and 250 spores for GSH) and inoculated on one side of a petal. The other side of the same petal was inoculated with the same number of spores with $0.4 \%$ methanol carrier as control. Data are from a single trial that was representative of two trials. Ten peach (cv. Loadel) petals were used in each treatment. Lesion sizes and number of petals with lesions were recorded $18 \mathrm{~h}$ postinoculation.

b Statistical analyses were done by paired $t$ tests of actual lesion area on 10 inoculated petals. $P$ values for the difference between the CA or GSH treatment values and their control are presented. Both CA and GSH significantly reduced lesion size relative to the control at concentrations 0.25 to $1 \mathrm{mM}$. in part by an effect on the activity of AP-1 or an AP-1-like transcription factor in Monilinia spp., leads to reduced transcription of the genes encoding cutinase and possibly PG. CA increases cellular GSH in animal cells (30), and CA and CGA also have been reported to increase the levels of GSH $S$-transferase, which conjugates GSH to other molecules. The P450-peroxidase catalyzed formation of hepatotoxic CA- and CGA-GSH conjugates has been reported to occur in vitro with isolated rat liver microsomes (28), and thus might occur in vivo too.

Total GSH, which includes conjugated GSH by the assay used in our study, significantly increased in $M$. fructicola cells after treatment of the cultures with CA, regardless of the medium used. Thus, addition of CA to the culture medium may have provided a reducing environment relative to the control, which is consistent with the observed changes in the redox potential of the medium following addition of $\mathrm{CA}$. Although $\mathrm{CA}$ inhibits the production of cutinase and PG, it remains to be established if cellular GSH provides a critical intermediary signal that modulates $M f_{c}$ utl expression in response to CA. It is also possible, although not evident from our experiments, that CA could induce a transient and localized oxidative stress. M. fructicola and related fungi produce laccases and other phenol oxidases that generate superoxide anion and hydrogen peroxide as transient intermediates during the reaction $(18,45)$. Such a stress, if perceived by the fungal cell, conceivably could trigger the associated changes in GSH metabolism (12).

Appressoria were shown to be required for full virulence of M. fructicola in almond and peach petals (25) and might serve as resting structures in stone fruits of intermediate maturity (i.e., stage II). CA and CGA also inhibited appressorium formation by M. fructicola. After treatment with CA, CGA, or GSH at $1 \mathrm{mM}$, the washed conidia were unable to germinate as well as the untreated control. However, the inhibition of germination was not observed with unwashed conidia used to inoculate petals and cherry fruit in this study or in an earlier study (6). Conidia that had been washed with water also had a dramatically increased frequency of formation of appressoria on a polystyrene surface (25). Washing could simply eliminate nutrients or other factors that in some way attenuate perception by the conidia of the $\mathrm{CA}$-induced changes in the external redox environment. Since the inhibition of cell wall degrading enzymes by phenols appears to be associated with changes in the redox potential, appressorium development might also be regulated in a redoxrelated manner, with inhibition coincident with high levels of intracellular GSH.

Appressorium formation and the expression of $M f c u t 1$ and Mfpgl are associated with Monilinia infection in some stone fruit tissues and appear to be required for successful infection of Prunus flower petals $(24,25)$. In the present study, CA and CGA inhibited production of cell wall degrading enzymes and appressoria in vitro, and significantly reduced lesion development when applied with conidia on both peach petals and cherry fruit. Taken together, these studies support a role for appressoria and cell wall degrading enzymes in brown rot disease development in some

TABLE 4. Reduction of brown rot lesion development by caffeic acid (CA) and reduced glutathione (GSH) on cherry fruit after inoculation with Monilinia fructicola ${ }^{\mathrm{a}}$

\begin{tabular}{|c|c|c|c|c|c|c|c|c|}
\hline \multirow[b]{2}{*}{ Cultivar } & \multicolumn{2}{|c|}{$\begin{array}{c}\text { Mean of lesion area }\left(\mathrm{mm}^{2}\right) \\
\text { (no. of fruit with lesions) }\end{array}$} & \multirow{2}{*}{$\begin{array}{l}\text { Paired } t \text { test }{ }^{\mathrm{b}} \\
(P \text { values })\end{array}$} & \multirow{2}{*}{$\begin{array}{c}\% \text { Reduction of } \\
\text { infected area by CA }\end{array}$} & \multicolumn{2}{|c|}{$\begin{array}{l}\text { Mean lesion area }\left(\mathrm{mm}^{2}\right) \\
\text { (no. of fruit with lesions) }\end{array}$} & \multirow{2}{*}{$\begin{array}{l}\text { Paired } t \text { test }{ }^{\mathrm{b}} \\
(P \text { values })\end{array}$} & \multirow{2}{*}{$\begin{array}{c}\% \text { Reduction of } \\
\text { infected area by GSH }\end{array}$} \\
\hline & Control & $\mathrm{CA}$ & & & Control & GSH & & \\
\hline Bing & $57.6(26)$ & $7.7(6)$ & $<0.0001$ & 87 & $46.9(25)$ & $11.1(8)$ & $<0.0001$ & 76 \\
\hline
\end{tabular}

${ }^{a}$ Reagent $(1 \mathrm{mM})$ was mixed with 500 conidia per 5 - $\mu$ d droplet and inoculated on one side of a cherry. The other side of the same cherry was inoculated with the same number of spores but with $0.4 \%$ methanol carrier as control. Values are the means from 30 cherries for each cultivar for each treatment. Results presented are from a single trial representative of at least two trials.

${ }^{\mathrm{b}}$ Statistical analyses were performed by paired $t$ tests of actual lesion sizes from 30 cherries. $P$ values for the difference between the CA or GSH treatment values relative to the control are presented. Both CA and GSH significantly reduced lesion size relative to the control in the two cultivars tested. 
host tissues, and host phenolic compounds may contribute to the regulation of these infection-related processes. Our experiments also indicate that appressoria form readily on stage II fruit surfaces, notwithstanding the high content of exocarp phenols (25). Thus, it appears that at this stage of infection inhibitory phenols are not perceived or are not available to the pathogen at sufficient concentration to affect the formation of these infection structures. If CGA and similar compounds are operative as we hypothesize, then they would act during or soon after initial penetration of the epicuticular surface. It may not be until further ingress and disruption of the epicuticular layer that phenols are released in sufficient amounts to arrest development of the nascent infection.

Identification of regulatory elements in pathways that lead to an arrested state in fungi could identify targets for new treatments or creative approaches for interfering with pathogenesis. For example, consistent with our hypothesis are the benefits derived by postharvest treatment with antioxidants such as butylated hydroxytoluene and butylated hydroxyanisole to delay the appearance of anthracnose disease in avocado fruit and of gray and white molds in various crops $(14,33,37)$. In contrast, the use of paraquat, which generates reactive oxygen species in plant tissue, is a well-established experimental treatment in stone fruits that permits development of $M$. fructicola for the detection of quiescent infections (31). Although the effects of antioxidants and pro-oxidants might be explained from the standpoint of altered host plant physiology, there may be profound effects on pathogen metabolism as well with respect to expression of factors required for ingress and colonization. Selected antioxidants might provide a suitable postharvest treatment to complement controlled atmosphere environments that are inhibitory to diseases caused by Monilinia spp. and related fungi $(2,13)$.

In conclusion, our results provide evidence for pronounced effects of fruit phenols on specific developmental stages of $M$. fructicola and that these effects may be mediated in part by changes in the redox environment. However, although our results are suggestive, a causal relationship between CGA and related phenolic compounds in fruit and a role in restricting the pathogen and/or maintaining quiescence in nascent infections is unresolved. There is a need for a model system(s) to better address issues related to the redox control of pathogen quiescence and developmental susceptibility of fruit. Nonetheless, the Monilinia-Prunus spp. interaction should be informative for guiding future research and for translating principles learned from model systems to the field.

\section{ACKNOWLEDGMENTS}

We thank K.-R. Chung, L. Epstein, T. Gordon, and J. Labavitch for critical review of the manuscript; S. Marek and P. Weyman for helpful discussions; T. Gradziel for providing plant material for some experiments; and S. Madden, M. Flores, and K. Yost for technical assistance with fruit analyses. Research supported in part by grants from the California Cling Peach Board and the U.S.-Israel BARD program.

\section{LITERATURE CITED}

1. Aguirre, J., Rios-Momberg, M., Hewitt, D., and Hansberg, W. 2005. Reactive oxygen species and development in microbial eukaryotes. Trends Microbiol. 13:111-118.

2. Ahmadi, H., Biasi, W. V., and Mitcham, E. J. 1999. Control of brown rot decay of nectarines with $15 \%$ carbon dioxide atmospheres. J. Am. Soc. Hortic. Sci. 124:708-712.

3. Alarco, A.-M., Balan, I., Talibi, D., Mainville, N., and Raymond, M. 1997. AP1-mediated multidrug resistance in Saccharomyces cerevisiae requires $f l r 1$ encoding a transporter of the major facilitator superfamily. J. Biol. Chem. 272:19304-19313.

4. Arrigo, A.-P. 1999. Gene expression and the thiol redox state. Free Radic. Biol. Med. 27:936-944.

5. Biggs, A. R., and Northover, J. 1988. Early and late-season susceptibility of peach fruits to Monilinia fructicola. Plant Dis. 72:1070-1074.
6. Bostock, R. M., Wilcox, S. M., Wang, G., and Adaskaveg, J. E. 1999. Suppression of Monilinia fructicola cutinase production by peach fruit surface phenolic acids. Physiol. Mol. Plant Pathol. 54:37-50.

7. Brady, C. J. 1993. Stone fruit. Pages 381-404 in: Biochemistry of Fruit Ripening. G. Seymour, J. Taylor, and G. Tucker, eds. Chapman \& Hall, London.

8. Brummell, D. A., Cin, V. D., Crisosto, C. H., and Labavitch, J. M. 2004. Cell wall metabolism during maturation, ripening and senescence of peach fruit. J. Exp. Bot. 55:2029-2039.

9. Byrde, R. J. W., Fielding, A. H., and Williams, A. H. 1960. The role of oxidized polyphenols in the varietal resistance of apples to brown rot. Pages 95-99 in: Plants, Health, and Disease. J. B. Pridham, eds. Pergamon Press, New York.

10. Chapman, G. W. J., Horvat, R. J., and Forbus, W. R. J. 1991. Physical and chemical changes during the maturation of peaches cultivar Majestic. J. Agric. Food Chem. 39:867-870.

11. Cheng, G. W., and Crisosto, C. H. 1995. Browning potential, phenolic composition, and polyphenoloxidase activity of buffer extracts of peach and nectarine skin tissue. J. Am. Soc. Hortic. Sci. 120:835-838.

12. Cnubben, N. H. P., Rietjens, I. M. C. M., Wortelboer, H., van Zanden, J., and van Bladeren, P. J. 2001. The interplay of glutathione-related processes in antioxidant defense. Environ. Toxicol. Pharmacol. 10:141152 .

13. Crisosto, C. H., Garner, D., and Crisosto, G. 2002. High carbon dioxide atmospheres affect stored "Thompson Seedless" table grapes. Hortscience 37:1074-1078

14. Elad, Y. 1992. The use of antioxidants (free radical scavengers) to control grey mould (Botrytis cinerea) and white mould (Sclerotinia sclerotiorum) in various crops. Plant Pathol. 41:417-426.

15. Fawcett, C. H., and Spencer, D. M. 1968. Sclerotinia fructigena infection and chlorogenic acid content in relation to antifungal compounds in apple fruits. Ann. Appl. Biol. 61:245-253.

16. Feng, R., Lu, Y., Bowman, L. L., Qian, Y., Castranova, V., and Ding, M. 2005. Inhibition of activator protein-1, nf- $\mathrm{b}$, and MAPKs and induction of phase 2 detoxifying enzyme activity by chlorogenic acid. J. Biol. Chem. 280:27888-27895.

17. Gross, K. C. 1982. A rapid and sensitive spectrophotometric method for assaying polygalacturonase using 2-cyanoacetamide. Hortscience 17:933934.

18. Guillen, F., Munoz, C., Gomez-Toribio, V., Martinez, A. T., and Martinez, M. J. 2000. Oxygen activation during oxidation of methoxyhydroquinones by laccase from Pleurotus eryngii. Appl. Environ. Microbiol. 66:170-175.

19. Hill, G., Stellwaag-Kittler, F., Huth, G., and Schloesser, E. 1981. Resistance of grapes in different developmental stages to Botrytis cinerea. Phytopathol. Z. 102:328-338.

20. Ibbotson-Darhower, H., Hickey, K. D., and Tarvis, J. W. 1998. Susceptibility of peach and nectarine fruit at different developmental stages to Monilinia fructicola. (Abstr.) Phytopathology 88(suppl.):S130.

21. Jersch, S., Scherer, C., Huth, G., and Schloesser, E. 1989. Proanthocyanidins as basis for quiescence of Botrytis cinerea in immature strawberry fruits. Z. Pflanzenkrankh. Pflanzenschutz 96:365-378.

22. Knegt, E., Vermeer, E., and Bruinsma, J. 1988. Conversion of the polygalacturonase isoenzymes from ripening tomato fruits. Physiol. Plant 72:108-114.

23. Kubota, N., Mimura, H., and Shimamura, K. 2000. Differences in phenolic levels among mature peach and nectarine cultivars and their relation to astringency. J. Jpn. Soc. Hortic. Sci. 69:35-39.

24. Lee, M.-H. 2005. Microscopic, physiological and molecular studies of pathogenesis in Monilinia fructicola, the brown rot pathogen of stone fruits. Ph.D. thesis. University of California, Davis.

25. Lee, M.-H., and Bostock, R. M. 2006. Induction, regulation, and role in pathogenesis of appressoria in Monilinia fructicola. Phytopathology 96:1072-1080.

26. Luo, Y., and Michailides, T. J. 2001. Factors affecting latent infection of prune fruit by Monilinia fructicola. Phytopathology 91:864-872.

27. Maggi-Capeyron, M.-F., Ceballos, P., Cristol, J.-P., Delbosc, S., Le Doucen, C., Pons, M., Leger, C. L., and Descomps, B. 2001. Wine phenolic antioxidants inhibit AP-1 transcriptional activity. J. Agric. Food Chem. 49:5646-5652.

28. Moridani, M. Y., Scobie, H., Jamshidzadeh, A., Salehi, P., and O’Brien, P. J. 2001. Caffeic acid, chlorogenic acid, and dihydrocaffeic acid metabolism: Glutathione conjugate formation. Drug Metab. Dispos. 29:14321439.

29. Nardini, M., Leonardi, F., Scaccini, C., and Virgili, F. 2001. Modulation of ceramide-induced $\mathrm{nf}-\kappa \mathrm{b}$ binding activity and apoptotic response by caffeic acid in U937 cells: Comparison with other antioxidants. Free Rad. Biol. Med. 30:722-733.

30. Nardini, M., Pisu, P., Gentili, V., Natella, F., Di Felice, M., Piccolella, E., and Scaccini, C. 1998. Effect of caffeic acid on tert-butyl hydroperoxide- 
induced oxidative stress in U937. Free Rad. Biol. Med. 25:1098-1105.

31. Northover, J., and Cerkauskas, R. F. 1994. Detection and significance of symptomless latent infections of Monilinia fructicola in plums. Can. J. Plant Pathol. 16:30-36.

32. Primiano, T., Sutter, T. R., and Kensler, T. W. 1997. Redox regulation of genes that protect against carcinogens. Comp. Biochem. Physiol. B Comp. Biochem. 118:487-497.

33. Prusky, D. 1988. The use of antioxidants to delay the onset of anthracnose and stem end decay in avocado fruits after harvest. Plant Dis. 72:381-384.

34. Prusky, D. 1996. Pathogen quiescence in postharvest diseases. Annu. Rev. Phytopathol. 34:413-434.

35. Prusky, D., and Keen, N. T. 1993. Involvement of preformed antifungal compounds in the resistance of subtropical fruits to fungal decay. Plant Dis. 77:114-119.

36. Prusky, D., Keen, N., Sims, J., and Midland, S. 1982. Possible involvement of an antifungal diene in the latency of Colletotrichum gloeosporioides on unripe avocado fruits. Phytopathology 72:1578-1582.

37. Prusky, D., Ohr, H. D., Grech, N., Campbell, S., Kobiler, I., Zauberman, G., and Fuchs, Y. 1995. Evaluation of antioxidant butylated hydroxyanisole and fungicide prochloraz for control of post-harvest anthracnose of avocado fruit during storage. Plant Dis. 79:797-800.

38. Prusky, D., and Yakoby, N. 2003. Pathogenic fungi: Leading or led by ambient pH? Mol. Plant Pathol. 4:509-516.

39. Quidde, T., Osbourn, A., and Tudzynski, P. 1998. Detoxification of $\alpha-$ tomatine by Botrytis cinerea. Physiol. Mol. Plant Pathol. 52:151-165.

40. Rodov, V., Ben-Yehoshua, S., Fang, D. Q., Kim, J. J., and Ashkenazi, R. 1995. Preformed antifungal compounds of lemon fruit: Citral and its relation to disease resistance. J. Agric. Food Chem. 43:1057-1061.

41. Saija, A., Tomaino, A., Lo Cascio, R., Trombetta, D., Proteggente, A., De
Pasquale, A., Uccella, N., and Bonina, F. 1999. Ferulic and caffeic acids as potential protective agents against photooxidative skin damage. J. Sci. Food Agric. 79:476-480.

42. Senter, S. D., and Callahan, A. 1990. Variability in the quantities of condensed tannins and other major phenols in peach fruit during maturation. J. Food Sci. 55:1585-1602.

43. Singleton, V., and Rossi, J. 1965. Colorimetry of total phenolics with phosphomolybdic-phophotungstic acid reagents. Am. J. Enol. Vitic. 16:144-158.

44. Singleton, V. L., and Trousdale, E. K. 1992. Anthocyanin-tannin interactions explaining differences in polymeric phenols between white and red wines. Am. J. Enol. Vitic. 43:63-70.

45. Slomczynski, D., Nakas, J. P., and Tanenbaum, S. W. 1995. Production and characterization of laccase from Botrytis cinerea 61-34. Appl. Environ. Microbiol. 61:907-912.

46. Tietze, F. 1969. Enzymic method for quantitative determination of nanogram amounts of total and oxidized glutathione applications to mammalian blood and other tissues. Anal. Biochem. 27:502-522.

47. Verhoeff, K., and Liem, J. 1975. Toxicity of tomatine to Botrytis cinerea, in relation to latency. Phytopathol. Z. 82:333-338.

48. Wang, G. Y., Michailides, T. J., Hammock, B. D., Lee, Y.-M., and Bostock, R. M. 2002. Molecular cloning, characterization, and expression of a redox-responsive cutinase from Monilinia fructicola (Wint.) Honey. Fungal Genet. Biol. 35:261-276.

49. Yagasaki, K., Miura, Y., Okauchi, R., and Furuse, T. 2000. Inhibitory effects of chlorogenic acid and its related compounds on the invasion of hepatoma cells in culture. Cytotechnology 33:229-235.

50. Zucconi, F. 1986. Peach. Pages 303-321 in: Handbook of Fruit Set and Development. S. P. Monselise, ed. CRC Press, Boca Raton, FL. 